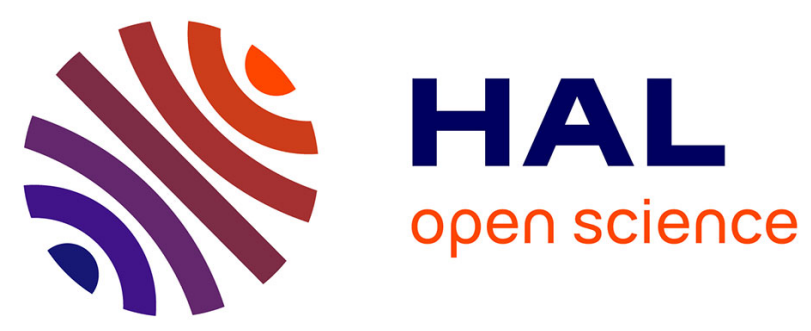

\title{
Significant improvement in the hydrogen storage capacity of a reduced graphene oxide/TiO 2 nanocomposite by chemical bonding of $\mathrm{Ti}-\mathrm{O}-\mathrm{C}$
}

\author{
Zahra Gohari-Bajestani, Alp Yürüm, Yuda Yürüm
}

\section{- To cite this version:}

Zahra Gohari-Bajestani, Alp Yürüm, Yuda Yürüm. Significant improvement in the hydrogen storage capacity of a reduced graphene oxide/ $\mathrm{TiO} 2$ nanocomposite by chemical bonding of $\mathrm{Ti}-\mathrm{O}-\mathrm{C}$. RSC Advances, 2016, 6 (39), pp.32831-32838. 10.1039/c6ra00944a . hal-02273555

\section{HAL Id: hal-02273555 \\ https://hal.science/hal-02273555}

Submitted on 29 Aug 2019

HAL is a multi-disciplinary open access archive for the deposit and dissemination of scientific research documents, whether they are published or not. The documents may come from teaching and research institutions in France or abroad, or from public or private research centers.
L'archive ouverte pluridisciplinaire HAL, est destinée au dépôt et à la diffusion de documents scientifiques de niveau recherche, publiés ou non, émanant des établissements d'enseignement et de recherche français ou étrangers, des laboratoires publics ou privés. 


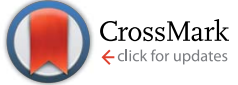

Cite this: RSC Adv., 2016, 6, 32831

Received 12th January 2016 Accepted 25th March 2016

DOI: $10.1039 / c 6 r a 00944 a$

www.rsc.org/advances

\section{Significant improvement in the hydrogen storage capacity of a reduced graphene oxide/ $/ \mathrm{TiO}_{2}$ nanocomposite by chemical bonding of $\mathrm{Ti}-\mathrm{O}-\mathrm{C} \uparrow$}

\begin{abstract}
Zahra Gohari Bajestani, ${ }^{a}$ Alp Yürüm ${ }^{\mathrm{b}}$ and Yuda Yürüm*a
A series of graphene-based nanocomposites with different $\mathrm{TiO}_{2}$ contents have been prepared via a facile chemical method. All nanocomposites were employed as hydrogen gas adsorption materials at room temperature and pressures up to 10 bar. The effect of dispersion state and size of the particles on the hydrogen storage capacity of nanocomposites was studied. The highest hydrogen uptake of 0.39 wt $\%$ was obtained among prepared nanocomposites and it is $125 \%$ higher than the hydrogen adsorption of the parent graphene material. This improvement can account for the presence of a high number of active sites needed for hydrogen molecules and the strong interaction between nanoparticles and graphene sheets.
\end{abstract}

\section{Introduction}

In recent years, production, storage, and consumption of energy have become a serious global problem. Hydrogen attracts considerable attention in the energy area since it can be a clean energy resource for the next-generation energy carriers in mobile and stationary power systems. ${ }^{1}$ However, finding materials for efficient hydrogen storage is one of the most important issues in future of renewable energies. ${ }^{2,3}$ Several candidates were studied during the last decades as safe and effective hydrogen adsorbents but none of them met the storage targets set by the U.S. Department of Energy (DOE).$^{4-6}$ Among these options, graphene a single atomic layer sheet of $\mathrm{sp}^{2}$ bonded carbon atoms, has been cited as a promising candidate for energy conversion and storage applications due to its high theoretically surface area, large microporosity, and good chemical stability. ${ }^{7-10}$ Nevertheless, the range of reported hydrogen uptakes of graphene at ambient conditions is low. ${ }^{11}$ Srinivas et al. ${ }^{12}$ and Huang et al. ${ }^{4}$ reached hydrogen uptake of $0.1 \mathrm{wt} \%$ at $10 \mathrm{bar}$ and $0.067 \mathrm{wt} \%$ at 57 bar, respectively. Thermodynamically, hydrogen molecules are incapable of penetrating between the graphene layers in graphitic structure whereby $\mathrm{H}_{2}$ adsorption generally restricts to the outermost sheets. Weak binding energy between carbon nanostructure and $\mathrm{H}_{2}$ at ambient conditions is also another key factor that leads to low $\mathrm{H}_{2}$ adsorption capacity of this material. ${ }^{8}$ Thus, surface modifications, such as doping and functionalization

${ }^{a}$ Faculty of Engineering and Natural Sciences, Sabanci University, Tuzla, Istanbul, 34956, Turkey. E-mail: yyurum@sabanciuniv.edu

${ }^{b}$ Sabanci University Nanotechnology Research and Application Center, Tuzla, Istanbul, 34956, Turkey

$\dagger$ Electronic supplementary information (ESI) available. See DOI: $10.1039 / \mathrm{c} 6 \mathrm{ra00944a}$ have been proposed to enhance gas adsorption property of graphene based materials., ${ }^{8,13}$ So far many theoretical and experimental studies have been devoted to functionalization of graphene by metals ${ }^{2,10,14,15}$ and metal oxides ${ }^{16-18}$ in which metal oxides offer a great scope for tailor-made carbonaceous adsorbents. Due to various advantages e.g., suppressing the restacking of graphene layers, good bonding and interfacial interactions with oxygen-containing groups on graphene sheets, fabrication of graphene/metal oxide is expected to be an effective and practical method toward increasing the hydrogen storage capacity of graphene. ${ }^{13,17}$

$\mathrm{TiO}_{2}$ has been widely studied due to its photochemical, catalytic and dielectric characteristics. Theoretical studies showed the potential of $\mathrm{Ti} / \mathrm{TiO}_{2}$-anchored carbonaceous materials $^{17,19,20}$ as a hydrogen storage material for room-temperature applications. Recent experimental results on $\mathrm{TiO}_{2}$-decorated expanded graphite ${ }^{21}$ and $\mathrm{TiO}_{2}$-carbon nanotubes (CNT) composites $^{22,23}$ revealed the enhanced electrochemical hydrogen uptake of graphene and higher $\mathrm{H}_{2}$ gas adsorption of CNT after impregnation with $\mathrm{TiO}_{2}$ nanoparticles.

In this work, $\mathrm{TiO}_{2}$-integrated graphene nanocomposites with different amounts of $\mathrm{TiO}_{2}$ nanoparticles were prepared via a facile chemical method. We focused on the hydrogen adsorption behavior of these nanocomposites at room temperature and low pressures that are relevant for practical on-board storage systems. Effects of the loading, dispersion state and size of nanoparticles on hydrogen storage capacity of nanocomposites were studied. Homogenous dispersion of $\mathrm{TiO}_{2}$ nanoparticles with diameter of $<20 \mathrm{~nm}$ was found to enhance the hydrogen storage capacity of parent graphene by $125 \%$. Higher hydrogen uptake of nanocomposites compared to that of graphene sample was related to strong attachment of highly distributed nanoparticles to the underlying graphene sheets. 


\section{Experimental section}

\subsection{Materials}

Natural graphite flake (99\%), sulfuric acid $\left(\mathrm{H}_{2} \mathrm{SO}_{4}, 98 \%\right)$, sodium nitrate $\left(\mathrm{NaNO}_{3}\right)$, potassium permanganate $\left(\mathrm{KMnO}_{4}\right)$ and hydrochloric acid ( $\mathrm{HCl}, 37 \%)$ were purchased from SigmaAldrich. Hydrogen peroxide $\left(\mathrm{H}_{2} \mathrm{O}_{2}, 30 \%\right)$ and titanium chloride $\left(\mathrm{TiCl}_{3}\right)$ were obtained from Merck. All reagents were analytical grade and used without further purification.

\subsection{Preparation}

Graphite oxide was prepared from natural graphite flakes using Hummers' method. ${ }^{24}$ In order to prepare $\mathrm{TiO}_{2}$-integrated graphene sheets, hereafter referred to as RGO-T nanocomposites, graphite oxide was first sonicated (Vibra Cell 75041, Bioblock Scientific) in water for $2 \mathrm{~h}$ to obtain a homogenous dispersion of graphene oxide (GO) in aqueous medium. Different amounts of $\mathrm{TiCl}_{3}$ were then added to the mixture to reach Ti loading of 3 $\mathrm{wt} \%, 5 \mathrm{wt} \%$, and $7 \mathrm{wt} \%$. After stirring for $24 \mathrm{~h}$, suspensions were filtered, vacuum-dried at $60{ }^{\circ} \mathrm{C}$ and reduced at $1000{ }^{\circ} \mathrm{C}$ for 12 min under argon atmosphere to obtain reduced graphene oxide (RGO) with different amounts of $\mathrm{TiO}_{2}$, named as RGO-T3, RGO$\mathrm{T} 5$, and RGO-T7 in accordance with increasing amount of $\mathrm{TiCl}_{3}$ in the mixing step. Thermogravimetric analysis indicated the presence of $\sim 10 \mathrm{wt} \%, \sim 12 \mathrm{wt} \%$ and $\sim 15 \mathrm{wt} \% \mathrm{TiO}_{2}$ in RGO-T3, RGO-T5, and RGO-T7, respectively (Fig. S1, ESI $\dagger$ ). As a reference, GO (without addition of $\mathrm{TiCl}_{3}$ ) was thermally reduced at $1000{ }^{\circ} \mathrm{C}$ to attain fully exfoliated reduced graphene oxide.

\subsection{Characterization}

X-Ray diffraction (XRD) patterns were performed using Bruker AXS diffractometer fitted with a Siemens X-ray gun using $0.15406 \mathrm{~nm} \mathrm{Cu} \mathrm{K} \alpha$ radiation. Raman spectroscopic analysis was carried out using Renishaw inVia reflex Raman spectrometer with a $532 \mathrm{~nm}$ laser beam in the range of $100-3500 \mathrm{~cm}^{-1}$ while samples were loaded on silicon wafer and focused with a $50 \times$ objectives. X-ray photoelectron spectroscopy (XPS) analyses were conducted on a Thermo K-alpha X-ray photoelectron spectrometer with a monochromated $\mathrm{Al} \mathrm{K \alpha}$ supported by a low energy electron/ion flood gun for charge neutralization. Transmission electron microscopy (TEM) micrographs and scanning electron microscopy (SEM) images were taken by Jeol 2000FX with the accelerating voltage of $200 \mathrm{kV}$ and Leo Supra 35VP field emission scanning electron microscope with an acceleration voltage of $2 \mathrm{kV}$, respectively. The Brunauer-Emmett-Teller (BET) specific surface area and porosity of samples were determined by analyzing the standard nitrogen adsorption isotherms at 77 K using nova 2200e, Quantachrome instruments. Hydrogen storage capacity of samples was measured by using Intelligent Gravimetric Analyzer (IGA 001, Hiden Isochema). All nanocomposites (20-25 mg) were degassed at $100{ }^{\circ} \mathrm{C}$ for $12 \mathrm{~h}$ under high vacuum $\left(\sim 10^{-7}\right.$ mbar $)$ prior to measurements and then, hydrogen adsorption isotherms were measured at $298 \mathrm{~K}$ up to 10 bar.

\section{Results and discussion}

\subsection{Materials characterization}

X-ray diffraction was first carried out to determine the crystallographic structure of the samples. As shown in Fig. 1a, natural

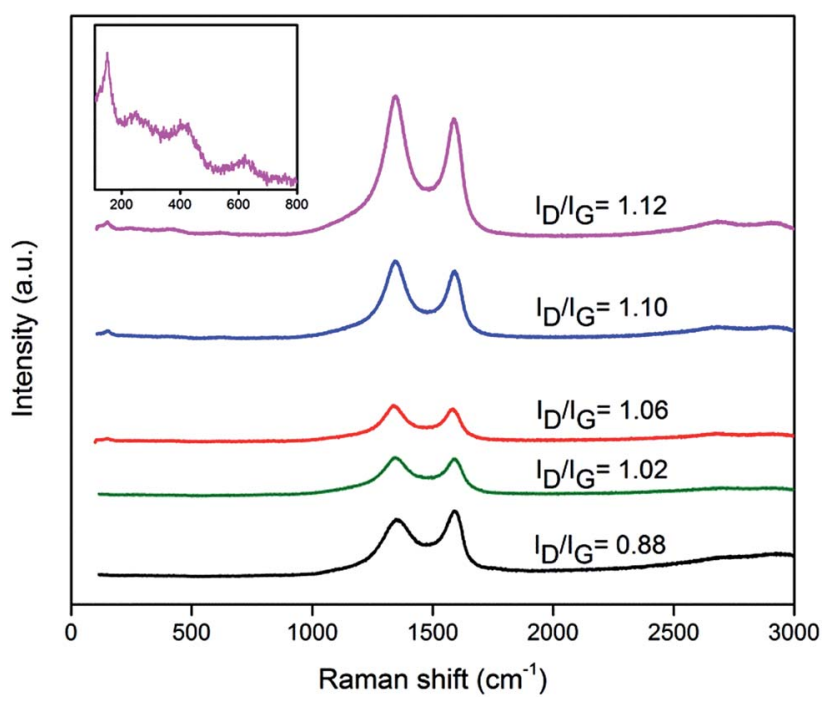

Fig. 2 Raman spectra of graphite oxide, RGO and RGO-T nanocomposites, from bottom to top: graphite oxide, RGO, RGO-T3, RGO-T5 and RGO-T7. Inset magnifies the wavenumber of 100-900 $\mathrm{cm}^{-1}$ in $\mathrm{RGO}-\mathrm{T} 7$ a)

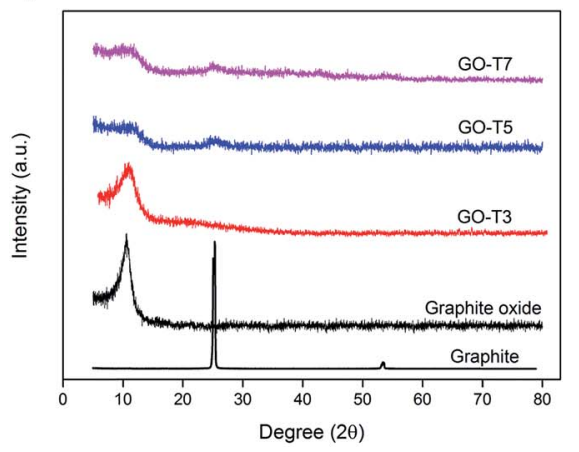

b)

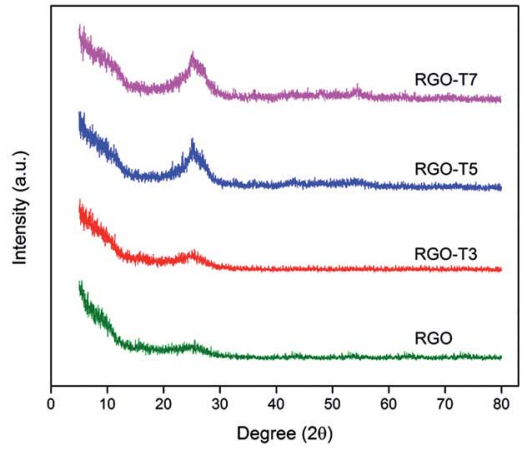

Fig. 1 XRD patterns of (a) GO and (b) RGO samples with increasing amount of Ti addition. 
graphite flakes show a sharp peak at $2 \theta=26^{\circ}$ that corresponds to (002) plane and an interlayer spacing ( $d$-spacing) of $3.3 \AA$. Upon oxidation, the (002) peak disappeared and a low intensity peak, indexed as (001), emerged at $2 \theta \approx 10.5^{\circ}$ with $d$-spacing of $8.4 \AA$ A. This increase of the $d$-spacing after oxidation has been correlated with intercalation of oxygen-containing groups between graphene layers that leads to change of the crystallographic structure of graphite. ${ }^{4}$ After inclusion of Ti, intensity and full width at half maximum (FWHM) of the characteristic peak of graphite oxide $\left(2 \theta \approx 10.5^{\circ}\right)$ were changed. In addition, a new peak centered at $2 \theta \approx 25^{\circ}$ was observed in GO-T5 and GO-T7 whereas no peak was detected at this region in GO-T3. Given the characteristic peak of $\mathrm{TiO}_{2}(101)$ at $2 \theta \approx 25^{\circ},{ }^{25}$ former observation can be attributed to formation of $\mathrm{TiO}_{2}$ in the samples. On the other hand, absence of this peak in GO-T3 can be related to the low metal content and/or small size of particles. ${ }^{4}$ Besides, progressive increase of FWHM and decrease of the intensity of GO main peak by Ti content suggests that GO was partially deoxygenated in the presence of $\mathrm{Ti}$ and reduced to turbostratic graphite. ${ }^{26}$ Consequently, appearance of the peak at $2 \theta \approx 25^{\circ}$ can also represent the formation of turbostratic graphite structures in the sample. Indeed, formation of turbostratic graphite coincides with the formation of $\mathrm{TiO}_{2}$ particle in specimens. According to Li et al., ${ }^{27}$ increase of FWHM of graphene layers correlates with non-uniformity in $d$-spacing, curvature and more importantly distortion of the layers. As a result, Ti component which intercalates between graphene oxide layers possibly forms structural defects in the system. Fig. 1b shows XRD patterns of thermally reduced GO samples before and after addition of Ti. Observation of a broad and low-
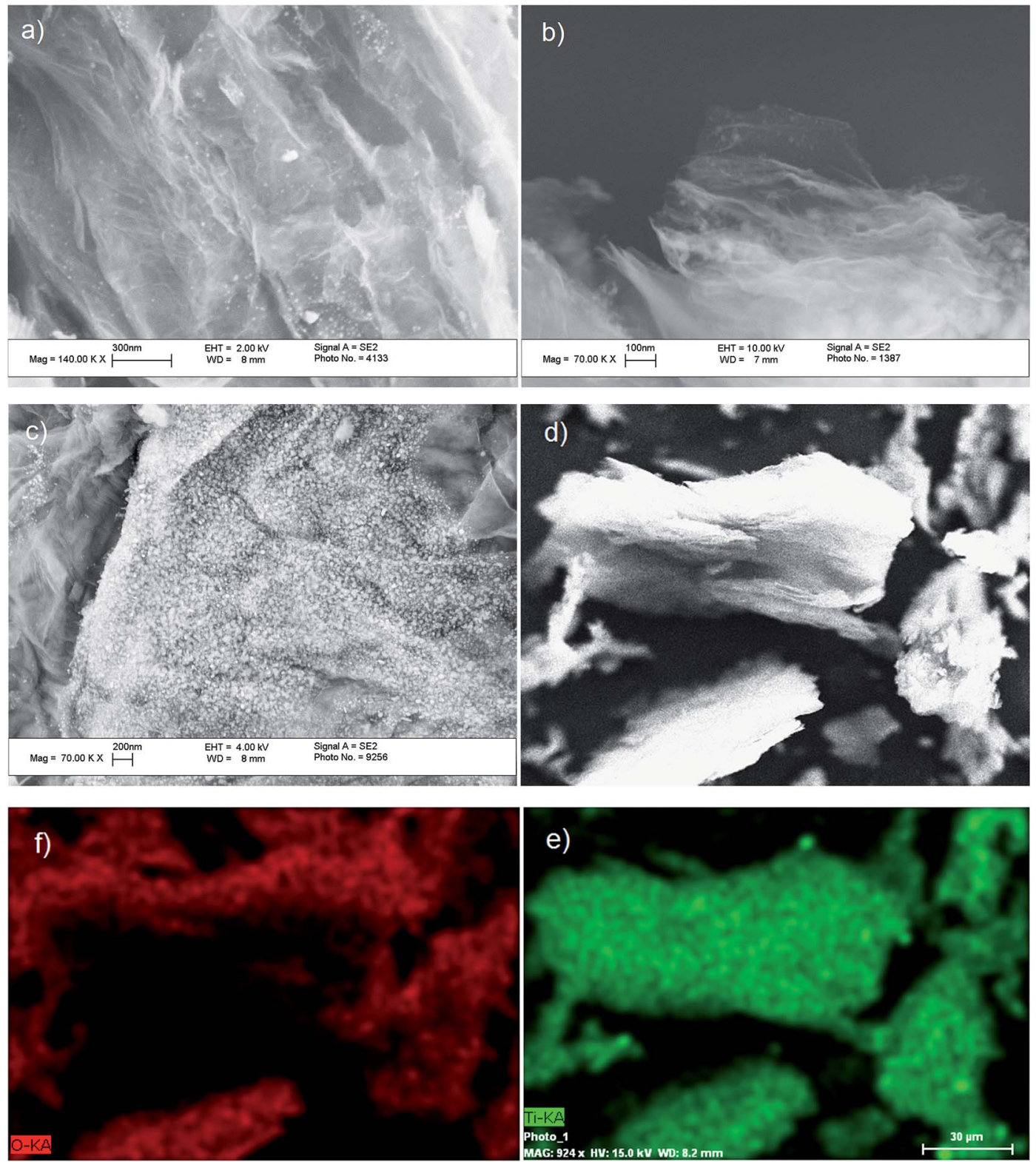

Fig. 3 (a) SEM images of RGO-T3, (b) RGO-T5, and (c) RGO-T7, (d) SEM image of RGO-T3 with low magnification, (e) Ti and (f) O elemental mapping of same area shown in (d). 

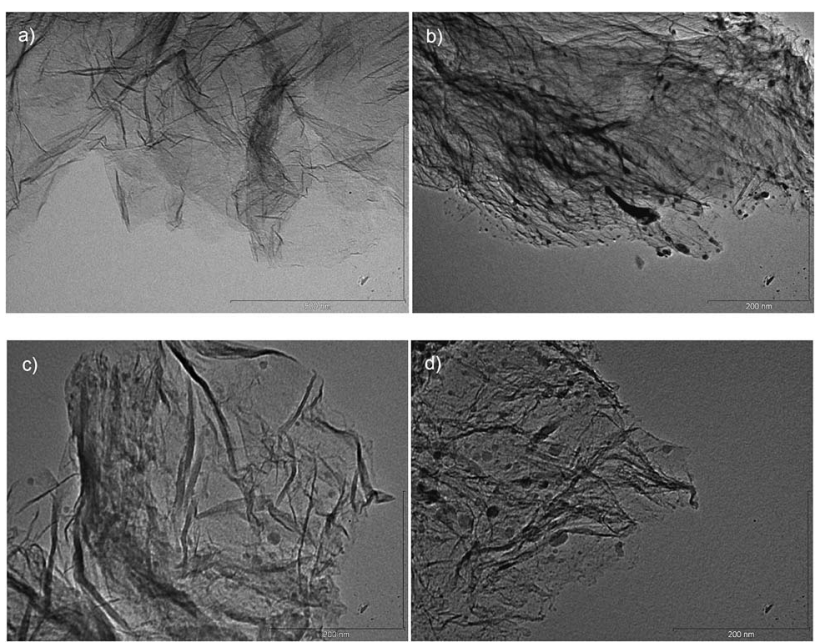

Fig. 4 TEM micrograph of (a) RGO, (b) RGO-T3, (c) RGO-T5, and (d) RGO-T7.

intensity (002) peak in the absence of (001) peak in RGO indicates the complete reduction of graphite oxide sheets and formation of poorly ordered graphene-like structure along the stacking direction. On the same basis, absence of GO peak at $\approx 10.5^{\circ}$ was used as a clear indication of reduction of graphite oxide sheets in RGO-T nanocomposites. ${ }^{25,28}$

Raman spectroscopy was used to study the structural properties of particles and quality of graphene sheets, particularly defects and order in the system. ${ }^{24}$ Fig. 2 displays the Raman spectra of graphite oxide, RGO and RGO-T nanocomposites with typical characteristic bands at $\sim 1600 \mathrm{~cm}^{-1}$ and $\sim 1350 \mathrm{~cm}^{-1}$, known as G-band and D-band, respectively. G-band corresponds to vibration of the $\mathrm{sp}^{2}$-bonded carbon atoms in a $2 \mathrm{D}$ hexagonal lattice while D-band represents in-plane stretching motion of symmetric $\mathrm{sp}^{2} \mathrm{C}-\mathrm{C}$ bonds. ${ }^{29,30}$ To analyze the degree of disorder in graphitic layers, intensity ratio of the $\mathrm{D}$ and $\mathrm{G}$ bands $\left(I_{\mathrm{D}} / I_{\mathrm{G}}\right)$ has been widely used in literature..$^{3,29,30}$ The $I_{\mathrm{D}} / I_{\mathrm{G}}$ value of 0.88 was calculated from the Raman spectrum of GO sample while higher $I_{\mathrm{D}} / I_{\mathrm{G}}$ values were observed in the Raman spectra of RGO and RGO-T nanocomposites. This increased $I_{\mathrm{D}} / I_{\mathrm{G}}$ ratio, points out the formation of additional defects during the deposition of particles that is a result of the interaction between particles and graphene sheets. ${ }^{3,31}$ Besides the $\mathrm{G}$ and $\mathrm{D}$ bands, a low intensity peak emerged at $151 \pm 1 \mathrm{~cm}^{-1}$ in RGO-T nanocomposites. This peak was assigned to $\mathrm{E}_{\mathrm{g}}$ mode of $\mathrm{TiO}_{2}$ and arises from the external vibration of anatase phase..$^{32-35}$ Inset of Fig. 2 magnifies the wavenumber of $100-900 \mathrm{~cm}^{-1}$ in RGO-T7 and shows two vibration peaks at $400 \mathrm{~cm}^{-1}\left(\mathrm{~B}_{1 \mathrm{~g}(1)}\right)$ and $635 \mathrm{~cm}^{-1}\left(\mathrm{E}_{\mathrm{g}(2)}\right)$ in addition to $\mathrm{E}_{\mathrm{g}}$ mode of $\mathrm{TiO}_{2}$. This observation confirms the formation of anatase $\mathrm{TiO}_{2}$ in RGO-T nanocomposites after thermal reduction process. $^{32-35}$ However, a large frequency blue-shift of $\mathrm{E}_{\mathrm{g}}$ was detected in RGO-T nanocomposites compared to $\mathrm{E}_{\mathrm{g}}$ of anatase single crystal $\left(144 \mathrm{~cm}^{-1}\right)$. A similar large frequency shift was also reported by Zheng et al. ${ }^{36}$ for $\mathrm{TiO}_{2}$ nanocrystals fabricated by solution chemical process. They showed when dimensions of $\mathrm{TiO}_{2}$ crystallites decrease to nanometer scale, frequency shift occurs in $\mathrm{E}_{\mathrm{g}}$ mode as a result of phonon confinement.
Distribution and size of the particles in RGO-T nanocomposites were studied using SEM, EDS and TEM. High magnification SEM images of samples (Fig. 3a-c) clearly demonstrate that the parent graphene sheets were coated with $\mathrm{TiO}_{2}$ nanoparticles. RGO-T3 and T5 display homogenous dispersion of nanoparticles while excess amount of Ti led to inhomogeneous deposition, growth and formation of submicron aggregation of nanoparticles in RGO-T7. The elemental analysis of RGO-T3 was provided in Fig. 3d-f as representative EDS results of RGO-T nanocomposites. Detection of distributed patterns of $\mathrm{Ti}$ and $\mathrm{O}$ in the elemental mapping confirms the homogeneous deposition of $\mathrm{TiO}_{2}$ nanoparticles throughout the sample.

TEM micrographs of RGO and RGO-T nanocomposites are presented in Fig. 4a-d. Wrinkled structured graphene sheets were clearly observed that indicates the formation of few layer graphene layers in all samples after thermal exfoliation. Homogeneous dispersion of $\mathrm{TiO}_{2}$ nanoparticles was detected as dark spots in TEM micrographs shown in Fig. 4b-d. Size of $\mathrm{TiO}_{2}$ nanoparticles in RGO-T3 was found to be $10 \pm 5 \mathrm{~nm}$ whereas higher amounts of $\mathrm{Ti}$ addition introduced higher average of particle sizes in RGO-T7. According to $\mathrm{Wu}$ et al. ${ }^{17}$ and Wang et al., ${ }^{37}$ size, morphology and anchoring of nanocrystals are dependent on the degree of oxidation of the underlying substrate. It is thought that Ti component could use the oxygen functional groups as nucleation centers. As a result, highly oxidized GO surface with high concentration of defects interacts strongly with particles and this strong pinning force hinders the diffusion and growth of formed particles. ${ }^{31,38}$ Tsao et al. ${ }^{39}$ showed that size of the catalyst particles plays an important role in $\mathrm{H}_{2}$ uptake in which $\mathrm{Pt}$ nanoparticles of 1-2 $\mathrm{nm}$ remarkably increased the $\mathrm{H}_{2}$ storage capacity of Pt/activated carbon nanocomposite. Therefore, formation of fine and distributed nanoparticles is highly preferred in order to increase the hydrogen adsorption capacity of RGO-T nanocomposites.

XPS measurement was performed to elucidate the chemical state of elements present in graphite oxide, RGO and RGO-T nanocomposites. Fig. 5a depicts a representative XPS survey spectrum (RGO-T5) that shows specimens mainly consist of $\mathrm{C}$ and $\mathrm{O}$ with no trace of contamination. The presence of Ti was detected in RGO-T nanocomposites with a weak signal at $\sim 459$ eV that corresponds to Ti 2 p electrons. ${ }^{40}$ Fig. 5 b depicts C 1 s XPS spectrum of graphite oxide with four peaks centered at 284.56, 285.02, 286.8 and $288.8 \mathrm{eV}$. These peaks were assigned to the $\mathrm{C}-\mathrm{C}$ (aromatic), ${ }^{41} \mathrm{C}-\mathrm{OH},{ }^{31} \mathrm{C}$ (epoxy/alkoxy) $/ \mathrm{C}=\mathrm{O}^{42}$ and $\mathrm{O}=\mathrm{C}-\mathrm{O}$ (carboxylic) ${ }^{35}$ groups respectively that imply the highly oxidized state of graphene sheets. After thermal reduction, the intensity of components associated with oxygenated functional groups significantly decreased (Fig. 5c). This decrease illustrates that most of the oxygen-containing functional groups are removed and GO is transformed to graphene. ${ }^{35}$ In Fig. 5d, Ti 2p XPS spectra of RGO-T nanocomposites exhibit two peaks centered at $464.7 \pm 0.1$ and $459 \pm 0.2 \mathrm{eV}$ assigned respectively to the Ti $2 \mathrm{p} 1$ and $\mathrm{Ti} 2 \mathrm{p} 3$ spin-orbital splitting photoelectrons in the $\mathrm{Ti}^{4+}$ state. The splitting energy between two Ti-bands was $5.69 \pm 0.02$ $\mathrm{eV}$ that is in agreement with the normal state of $\mathrm{Ti}^{\mathbf{4 +}} \cdot{ }^{\mathbf{2 5 , 4 3 , 4 4}}$ As $\mathrm{TiO}_{2}$ content was increased, Ti 2p3 peak narrowed (decrease of 
FWHM) and binding energies of Ti $2 p$ feature shifted toward higher binding energies. According to Oh et al., ${ }^{45}$ increasing thickness of deposited $\mathrm{TiO}_{2}$ shifts the bonding energy of Ti core level to higher values and decreases the FWHM of Ti 2p3 peak. Therefore, observation of shifting and narrowing Ti $2 \mathrm{p} 3$ peak with Ti content can be related to change of the dimensions of nanoparticles that is in agreement with TEM micrographs of RGO-T nanocomposites.

C 1s XPS spectra of RGO-T nanocomposites are presented in Fig. 5e with superimposition of C 1s XPS of RGO for comparison. All RGO-T nanocomposites show the main peak at $284.7 \pm$ $0.2 \mathrm{eV}$ (C-C aromatic band) in which the FWHM of the peak increased from $1.02 \mathrm{eV}$ in RGO to 1.3, 2.01 and $1.9 \mathrm{eV}$ in RGO-
T3, T5 and T7, respectively. The FWHM of the C 1s core level band has been used to evaluate the degree of chemical and structural heterogeneity in environment of carbon atoms. ${ }^{46,47}$ Therefore, it can be concluded that environment of carbon atoms becomes more heterogeneous through the addition of $\mathrm{Ti}$ suggesting the bonding of $\mathrm{TiO}_{2}$ nanoparticles with $\mathrm{C}$ atoms of graphene sheets.

To further support the presence of this bonding, O 1s XPS spectra of graphite oxide and RGO-T nanocomposites are depicted in Fig. 5f. The $\mathrm{O} 1 \mathrm{~s}$ spectrum of graphite oxide shows a peak centered at $532.5 \mathrm{eV}$ that is closely related to the hydroxyl groups on the surface of graphite oxide sheets. However, this peak shifted to $530.6 \pm 0.1 \mathrm{eV}$ in RGO-T nanocomposites. In a)

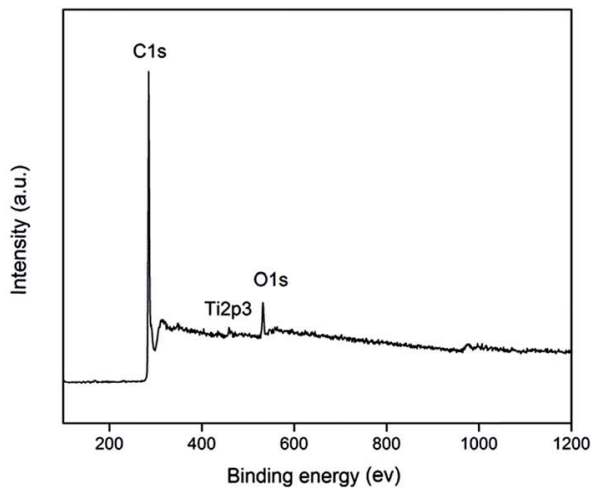

c)

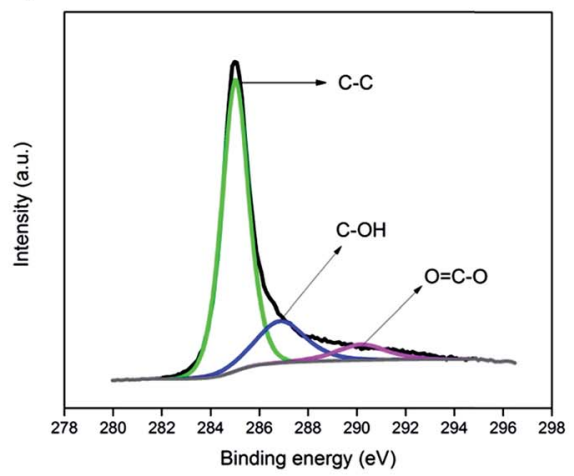

b)

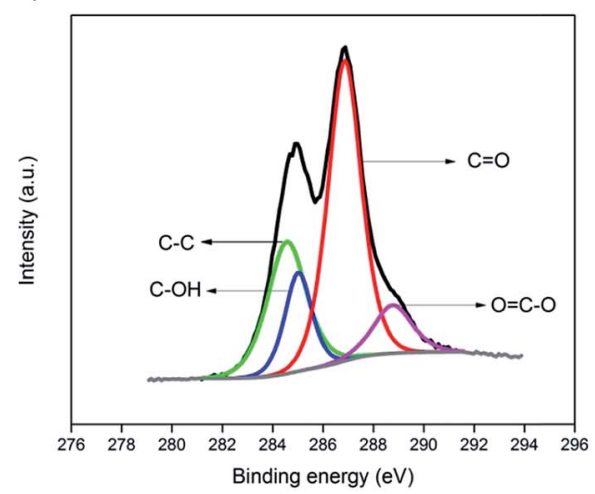

d)
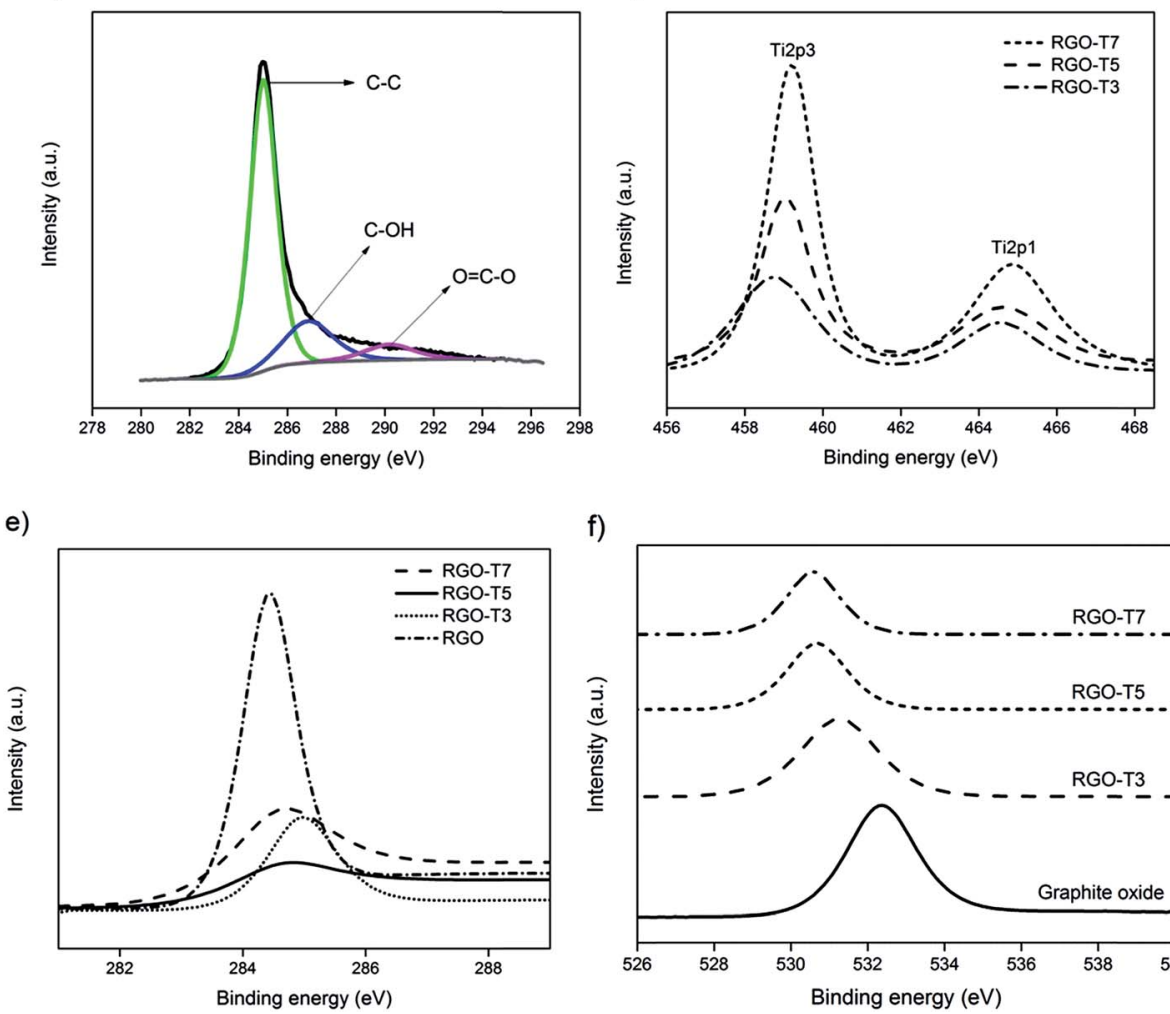

f)

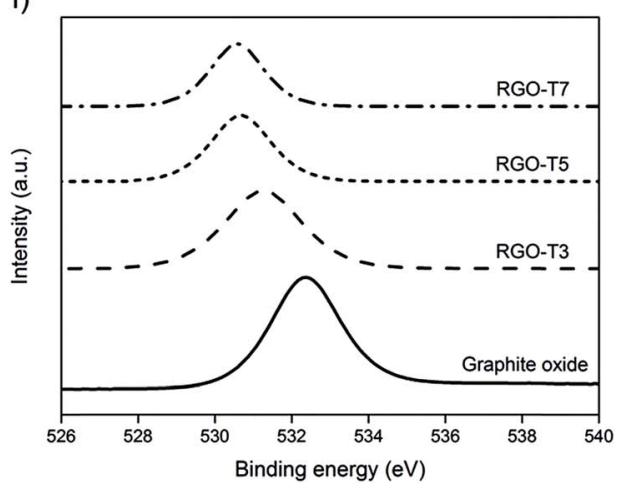

Fig. 5 (a) XPS survey spectra, (b) C 1s XPS spectrum of graphite oxide, (c) C 1s XPS spectrum of RGO, (d) Ti 2p XPS spectra of RGO-T, (e) C 1s XPS spectra of RGO-T nanocomposite, and ( $f$ ) O 1s XPS spectra of graphite oxide and RGO-T nanocomposites. 
agreement with previous reports in bonding of $\mathrm{Ti}$ atoms with any available oxygen to form $\mathrm{TiO}_{2},{ }^{48,49}$ this peak was assigned as bonding energy of $\mathrm{O}$ in $\mathrm{Ti}-\mathrm{O}-\mathrm{C}$ bond. ${ }^{50,51}$ As a result, bonding between $\mathrm{Ti}, \mathrm{O}$, and $\mathrm{C}$ confirms the integration of nanoparticles into graphene sheets.

\subsection{Gas adsorption behavior}

Nitrogen adsorption-desorption isotherm was employed to characterize the specific surface area and pore structure of nanocomposites (Fig. 6a). According to the IUPAC classification, all samples showed a nature of type IV curve, that is, a low $\mathrm{N}_{2}$ adsorption capacity at low relative pressure $\left(P / P_{0}\right)$ followed by a hysteresis loop at high $P / P_{0}$. The former indicates the presence of small number of micropores while the latter reflects the formation of mesoporous structures in the system. ${ }^{52}$ Higher $\mathrm{N}_{2}$ adsorption of pristine graphene than that of RGO-T illustrates the lower adsorption capability of RGO after deposition of nanoparticles when physical adsorption is the dominant process. $^{2}$

The Brunauer-Emmett-Teller (BET) and Barret-JoynerHalenda (BJH) methods were applied to determine the specific surface area and pore structure, respectively. The pore-size distribution isotherm of RGO (Fig. 6b) displayed one peak concentrated in 2-5 nm. After incorporation of nanoparticles, the main peak was weakened and an extra peak emerged at lower radius $(\sim 1 \mathrm{~nm})$. Moreover, significant decrease in average pore size was detected after addition of $\mathrm{Ti}$ to the samples (Table 1). As a result, the reduction in specific surface area and average pore size can be attributed to the partial blockage of mesopores by $\mathrm{TiO}_{2}$ nanoparticles. ${ }^{53}$

Fig. 7 presents the hydrogen adsorption isotherms of RGO and RGO-T nanocomposites at $298 \mathrm{~K}$. As expected, the hydrogen uptake of all samples increased by hydrogen pressure. The parent graphene sample showed hydrogen uptake of 0.17 wt $\%$ at 10 bar. After $\mathrm{TiO}_{2}$-integration, the hydrogen storage capacity of 0.39 wt\% was obtained by RGO-T5 that is $125 \%$ higher than that of pristine graphene. Further addition of $\mathrm{Ti}$ (RGO-T7) caused a decrease in hydrogen adsorption, possibly owing to aggregation of nanoparticles and losing porosity/ surface area.
Table 1 Specific surface area and pore diameter of RGO and RGO-T nanocomposites

\begin{tabular}{llc}
\hline & Specific surface area $\left(\mathrm{m}^{2} \mathrm{~g}^{-1}\right)$ & Pore diameter $(\AA)$ \\
\hline RGO & 461.76 & 25.5 \\
RGO-T3 & 371.31 & 8.1 \\
RGO-T5 & 219.35 & 8.3 \\
RGO-T7 & 207.50 & 7.8
\end{tabular}

The enhanced hydrogen storage capacity of the nanocomposites cannot be attributed to differences between the surface areas of samples since all nanocomposites displayed lower BET specific surface area than RGO (Fig. 6a). In addition, comparison of hydrogen adsorption isotherms at $298 \mathrm{~K}$ reveals the change of the shape of the adsorption curves from concave in pristine graphene to relatively linear in RGO-T samples. $\mathrm{Li}$ et $a l .{ }^{54}$ found that linear adsorption isotherm is the characteristic behavior of hydrogen spillover on nearly all adsorbents and is very different from that of physical adsorptions characterized by an isotherm concave to the pressure axis. Thus, the higher hydrogen adsorption capacity of RGO-T nanocomposites originates from a process other than physical adsorption. Wang et $a .^{19,55}$ have shown by the first-principle computations that strongly anchored $\mathrm{Ti}$ atoms on surface of GO template are superior sites for hydrogen adsorption whereby each Ti atom can bind multiple $\mathrm{H}_{2}$ with the binding energies of 14-41 $\mathrm{kJ} \mathrm{mol}{ }^{-1} \mathrm{H}_{2}$. Results of hydrogen storage measurement obtained by Mishra et al., ${ }^{56}$ Zhang et al. ${ }^{22}$ and Lueking and Yang ${ }^{57}$ suggest the contribution of chemical adsorption in hydrogen uptake of different carbonaceous materials after incorporation of $\mathrm{TiO}_{2}$. They showed that this contribution can be attributed to non-classical s-p-d hybridization. ${ }^{22}$ As a result, higher hydrogen storage capacity of RGO-T nanocomposites compared to pristine graphene can be linked to the activation of processes usually grouped as chemisorption. Lueking and Yang $^{57}$ have also underscored the role of catalyst-support interaction for improvement of hydrogen uptake of composites in which simple mixing of metal particles with support does not improve the hydrogen uptake of the system. Besides, Choucair and Mauron $^{58}$ reported decrease in hydrogen uptake of graphene at a)

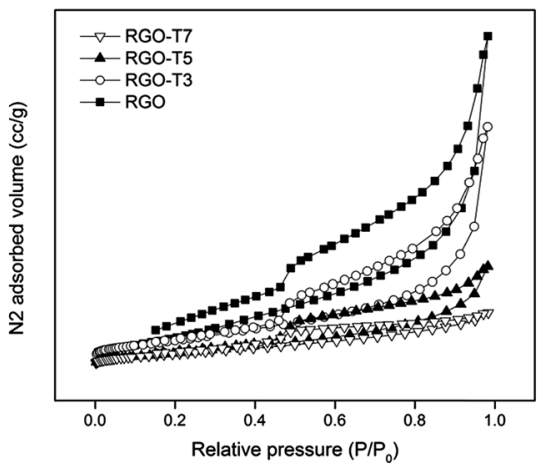

b)

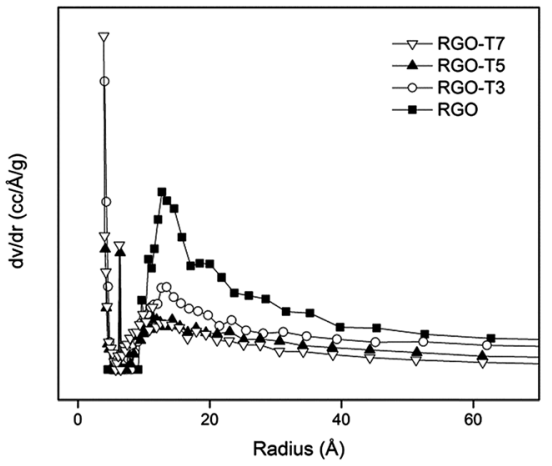

Fig. 6 (a) $\mathrm{N}_{2}$ adsorption isotherms and (b) pore size distribution of RGO and RGO-T nanocomposites. 


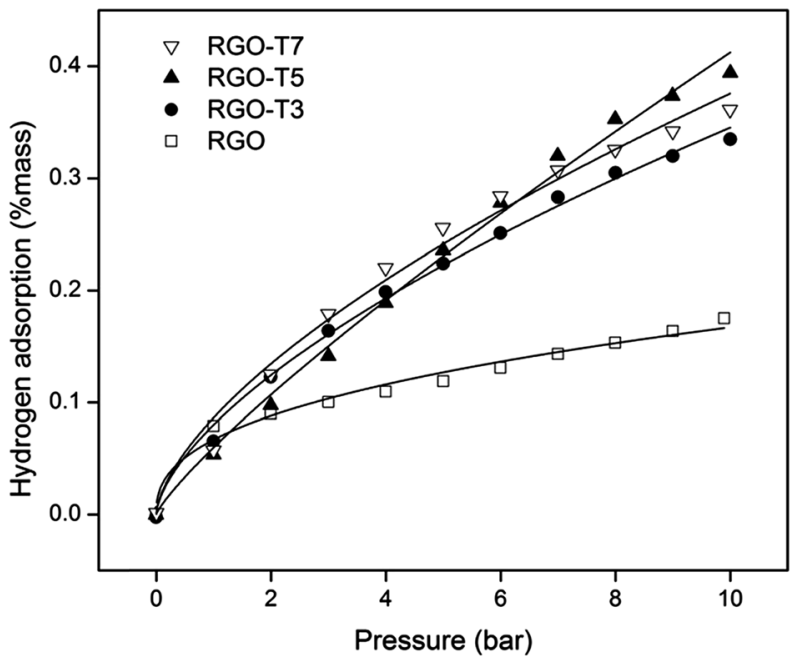

Fig. 7 Hydrogen adsorption isotherms RGO and RGO-T nanocomposites.

$77 \mathrm{~K}$ and $1 \mathrm{~atm} \mathrm{H}_{2}$ pressure after mechanical mixing with $1 / 1$ weight ratio $\mathrm{TiO}_{2}$ nanoparticles. Given the importance of particle size ${ }^{39}$ and dispersion of nanoparticles, ${ }^{59}$ strong attachment of highly distributed nanoparticles to the underlying graphene sheets was found to be essential to improve the hydrogen uptake of graphene/metal oxide nanocomposites.

\section{Conclusions}

In this work, a series of $\mathrm{TiO}_{2}$-integrated reduced graphene oxide composites with different amounts of $\mathrm{TiO}_{2}$ were prepared via a facile chemical impregnation method. By observation of TEM micrographs, $\mathrm{TiO}_{2}$ nanoparticles with diameter of less than $20 \mathrm{~nm}$ were homogeneously dispersed on the graphene sheets. The effect of metal oxide content on hydrogen adsorption of nanocomposites at ambient temperature and pressures up to 10 bar was studied. It was shown that strong interaction of metal oxide nanoparticles with the support, smaller particle size, and high dispersion of nanoparticles are necessary to promote the hydrogen storage capacity of nanocomposites. The highest storage capacity of $0.39 \mathrm{wt} \%$ was obtained among all nanocomposites and it is $125 \%$ higher than that of parent graphene material. This significant improvement of hydrogen adsorption compared to $\mathrm{RGO}-\mathrm{TiO}_{2}$ obtained by mechanical mixing (reported by ref. 58) was correlated with the formation of $\mathrm{Ti}-\mathrm{O}-\mathrm{C}$ bonding between nanoparticles and graphene substrate. We believe that the use of oxygen functional groups of graphene oxide sheets to form this bonding can also be extended to other types of metal oxide/ carbonaceous nanocomposites.

\section{Acknowledgements}

Zahra Gohari would like to thank PhD student Omid Akhlaghi for SEM and EDS characterizations.

\section{References}

1 K. Spyrou, D. Gournis and P. Rudolf, ECS J. Solid State Sci. Technol., 2013, 2, M3160-M3169.

2 C.-H. Chen, T.-Y. Chung, C.-C. Shen, M.-S. Yu, C.-S. Tsao, G.-N. Shi, C.-C. Huang, M.-D. Ger and W.-L. Lee, Int. J. Hydrogen Energy, 2013, 38, 3681-3688.

3 A. Ambrosi, A. Bonanni, Z. Sofer, J. S. Cross and M. Pumera, Chem.-Eur. J., 2011, 17, 10763-10770.

4 C.-C. Huang, N.-W. Pu, C.-A. Wang, J.-C. Huang, Y. Sung and M.-D. Ger, Sep. Purif. Technol., 2011, 82, 210-215.

5 H.-P. Zhang, X.-G. Luo, X.-Y. Lin, X. Lu and Y. Leng, Int. J. Hydrogen Energy, 2013, 38, 14269-14275.

6 B. P. Vinayan, K. Sethupathi and S. Ramaprabhu, Int. J. Hydrogen Energy, 2013, 38, 2240-2250.

7 H.-J. Choi, S.-M. Jung, J.-M. Seo, D. W. Chang, L. Dai and J.-B. Baek, Nano Energy, 2012, 1, 534-551.

8 S. Gadipelli and Z. X. Guo, Prog. Mater. Sci., 2015, 69, 1-60. 9 W. G. Hong, B. H. Kim, S. M. Lee, H. Y. Yu, Y. J. Yun, Y. Jun, J. B. Lee and H. J. Kim, Int. J. Hydrogen Energy, 2012, 37, 7594-7599.

10 L. Ma, J.-M. Zhang and K.-W. Xu, Appl. Surf. Sci., 2014, 292, 921-927.

11 A. G. Klechikov, G. Mercier, P. Merino, S. Blanco, C. Merino and A. V. Talyzin, Microporous Mesoporous Mater., 2015, 210, 46-51.

12 G. Srinivas, Y. Zhu, R. Piner, N. Skipper, M. Ellerby and R. Ruoff, Carbon, 2010, 48, 630-635.

13 V. Tozzini and V. Pellegrini, Phys. Chem. Chem. Phys., 2013, 15, 80-89.

14 A. Lebon, J. Carrete, L. J. Gallego and A. Vega, Int. J. Hydrogen Energy, 2015, 40, 4960-4968.

$15 \mathrm{~J}$. Lu, Y. Guo, Y. Zhang, Y. Tang and J. Cao, J. Solid State Chem., 2015, 231, 53-57.

16 Z. Wang and C.-J. Liu, Nano Energy, 2015, 11, 277-293.

17 Z.-S. Wu, G. Zhou, L.-C. Yin, W. Ren, F. Li and H.-M. Cheng, Nano Energy, 2012, 1, 107-131.

18 S. Yang, Y. Sun, L. Chen, Y. Hernandez, X. Feng and K. Müllen, Sci. Rep., 2012, 2, 427.

19 L. Wang, K. Lee, Y.-Y. Sun, M. Lucking, Z. Chen, J. J. Zhao and S. B. Zhang, ACS Nano, 2009, 3, 2995-3000.

20 E. Liu, Y. Gao, N. Zhao, J. Li, C. He and C. Shi, J. Appl. Phys., 2013, 113, 153708.

$21 \mathrm{Y} . \mathrm{Yu}, \mathrm{N}$. Zhao, C. Shi, C. He, E. Liu and J. Li, Int. J. Hydrogen Energy, 2012, 37, 5762-5768.

22 Z. Zhang, J.-Y. Hwang, M. Ning and X. Li, Int. J. Hydrogen Energy, 2012, 37, 16018-16024.

23 S.-U. Rather, N. Mehraj-ud-din, R. Zacharia, S. W. Hwang, A. R. Kim and K. S. Nahm, Int. J. Hydrogen Energy, 2009, 34, 961-966.

24 H. L. Poh, F. Sanek, A. Ambrosi, G. Zhao, Z. Sofer and M. Pumera, Nanoscale, 2012, 4, 3515-3522.

25 M. S. A. Sher Shah, A. R. Park, K. Zhang, J. H. Park and P. J. Yoo, ACS Appl. Mater. Interfaces, 2012, 4, 3893-3901.

$26 \mathrm{~S} . \mathrm{Li}, \mathrm{Z}$. Chen, Y. Jin, S. Chen, H. Wang, J. Geng, Q. Song, X. Yang, L. Ma, S. Li, Z. Qin and C. Zheng, Solid State Sci., 2011, 13, 862-866. 
27 Z. Q. Li, C. J. Lu, Z. P. Xia, Y. Zhou and Z. Luo, Carbon, 2007, 45, 1686-1695.

28 A. Dhanabalan, X. Li, R. Agrawal, C. Chen and C. Wang, Nanomaterials, 2013, 3, 606.

29 M. Giovanni, H. L. Poh, A. Ambrosi, G. Zhao, Z. Sofer, F. Sanek, B. Khezri, R. D. Webster and M. Pumera, Nanoscale, 2012, 4, 5002-5008.

$30 \mathrm{X}$. Wang and X. Zhang, Electrochim. Acta, 2013, 112, 774-782.

31 G. Compagnini, P. Russo, F. Tomarchio, O. Puglisi, L. D'Urso and S. Scalese, Nanotechnology, 2012, 23, 505601.

32 C. Chang-Jun, X. Mao-Wen, B. Shu-Juan, J. Chen-Chen, L. Zhen-Jiang and J. Dian-Zeng, Nanotechnology, 2013, 24, 275602.

33 H. C. Choi, Y. M. Jung and S. B. Kim, Vib. Spectrosc., 2005, 37, 33-38.

$34 \mathrm{H}$. Yoshitake and D. Abe, Microporous Mesoporous Mater., 2009, 119, 267-275.

35 K. Li, T. Chen, L. Yan, Y. Dai, Z. Huang, J. Xiong, D. Song, Y. Lv and Z. Zeng, Colloids Surf., A, 2013, 422, 90-99.

36 W. F. Zhang, Y. L. He, M. S. Zhang, Z. Yin and Q. Chen, J. Phys. D: Appl. Phys., 2000, 33, 912.

37 H. Wang, J. T. Robinson, G. Diankov and H. Dai, J. Am. Chem. Soc., 2010, 132, 3270-3271.

38 C. Xu and X. Wang, Small, 2009, 5, 2212-2217.

39 C.-S. Tsao, Y.-R. Tzeng, M.-S. Yu, C.-Y. Wang, H.-H. Tseng, T.-Y. Chung, H.-C. Wu, T. Yamamoto, K. Kaneko and S.-H. Chen, J. Phys. Chem. Lett., 2010, 1, 1060-1063.

40 I. Iatsunskyi, M. Kempiński, G. Nowaczyk, M. Jancelewicz, M. Pavlenko, K. Załęski and S. Jurga, Appl. Surf. Sci., 2015, 347, 777-783.

41 L. Yue-Wen, G. Meng-Xue, F. Lan, D. Shun-Liu, B. Jian-Feng, X. Su-Yuan, C. Zhong, H. Rong-Bin and Z. Lan-Sun, Nanotechnology, 2013, 24, 025604.

42 P. Wang, Y. Zhai, D. Wang and S. Dong, Nanoscale, 2011, 3, 1640-1645.
43 X. Bai, X. Zhang, Z. Hua, W. Ma, Z. Dai, X. Huang and H. Gu, J. Alloys Compd., 2014, 599, 10-18.

44 S. Bourgeois, P. le Seigneur and M. Perdereau, Surf. Sci., 1995, 328, 105-110.

45 W. S. Oh, C. Xu, D. Y. Kim and D. W. Goodman, J. Vac. Sci. Technol., A, 1997, 15, 1710-1716.

46 R. Rozada, J. Paredes, S. Villar-Rodil, A. Martínez-Alonso and J. D. Tascón, Nano Res., 2013, 6, 216-233.

47 S. Villar-Rodil, J. I. Paredes, A. Martinez-Alonso and J. M. D. Tascon, J. Mater. Chem., 2009, 19, 3591-3593.

48 A. Felten, I. Suarez-Martinez, X. Ke, G. Van Tendeloo, J. Ghijsen, J.-J. Pireaux, W. Drube, C. Bittencourt and C. P. Ewels, ChemPhysChem, 2009, 10, 1799-1804.

49 M. C. Biesinger, L. W. M. Lau, A. R. Gerson and R. S. C. Smart, Appl. Surf. Sci., 2010, 257, 887-898.

50 W.-S. Wang, D.-H. Wang, W.-G. Qu, L.-Q. Lu and A.-W. Xu, J. Phys. Chem. C, 2012, 116, 19893-19901.

51 T. S. Sreeprasad, S. M. Maliyekkal, K. P. Lisha and T. Pradeep, J. Hazard. Mater., 2011, 186, 921-931.

52 R. I. Masel, Principles of Adsorption and Reaction on Solid Surfaces, John Wiley \& Sons, 1996.

53 M.-S. Park, J.-S. Yu, K. J. Kim, G. Jeong, J.-H. Kim, Y.-N. Jo, U. Hwang, S. Kang, T. Woo and Y.-J. Kim, Phys. Chem. Chem. Phys., 2012, 14, 6796-6804.

54 Y. Li, F. H. Yang and R. T. Yang, J. Phys. Chem. C, 2007, 111, 3405-3411.

55 L. Wang, J. Zhao, L. Wang, T. Yan, Y.-Y. Sun and S. B. Zhang, Phys. Chem. Chem. Phys., 2011, 13, 21126-21131.

56 M. Amrita, B. Subarna, K. M. Susanta, A. G. Olivia and M. Mano, Nanotechnology, 2008, 19, 445607.

57 A. Lueking and R. T. Yang, J. Catal., 2002, 206, 165-168.

58 M. Choucair and P. Mauron, Int. J. Hydrogen Energy, 2015, 40, 6158-6164.

59 L. Zubizarreta, J. A. Menéndez, J. J. Pis and A. Arenillas, Int. J. Hydrogen Energy, 2009, 34, 3070-3076. 